\title{
Hypnotic experience is related to emotional contagion ${ }^{1,2}$
}

\section{Etzel CARDEÑA}

Devin B. TERHUNE

Angelica LÖÖF

Sandra BURATTI ${ }^{3}$

Department of Psychology, Lund University, Lund, Sweden

${ }^{1}$ This project was made possible by grant \#150-04 from the Bial Foundation to the first author.

${ }^{2}$ We thank Susanna Vestberg, Ph.D., for assisting with data collection, and Steven Jay Lynn, Ph.D., for valuable editorial suggestions.

${ }^{3}$ Address correspondence to Etzel Cardeña, Ph.D., Thorsen Professor, Department ofPsychology, Center for Research on Consciousness and Anomalous Psychology (CERCAP), Lund University, P.O. Box 213 SE-221 00, Lund, Sweden. E-mail: Etzel. Cardena@psychology.lu.se

\begin{abstract}
The authors conducted 2 studies to evaluate whether emotional contagion, the propensity to automatically imitate the emotional expressions of others and experience the corresponding emotions, is related to behavioral and experiential indices of hypnotizability and whether such a relationship is influenced by administration con- text. In Study 1, behavioral and subjective measures of hypnotizability were measured alongside emotional contagion in the same context. In Study 2, different measures of hypnotizability and hypnotic depth were administered, whereas emotional contagion was independently measured in a different (nonhypnotic) context. Emotional contagion correlated with behavioral and experiential indices of hypnotizability in Study 1 but only with the latter in Study 2. The authors interpret the results as reflecting a positive relationship between emotional contagion and, at least, experiential features of hypnotizability and strengthening the case for the importance of affectivity in hypnotic responsiveness.
\end{abstract}


Emotional contagion (EC) has been defined as a phenomenon in which people automatically mimic and/or synchronize their facial expressions, voices, postures, movements, and instrumental emotional behavior with those of others; such changes are seen as producing a similar mood to that of the observed person(s) (Hatfield, Cacioppo, \& Rapson, 1994). The resultant synchrony in physiological responses may underlie automatic empathy and accurate inferences about other people's emotions (Levenson \& Ruef, 1997) and some group processes (Barsade, 2002).

Various studies have found support for this construct. In one, it was found that after viewing videotapes with a person displaying specific emotional expressions, participants exhibited congruent moods to the respective stimuli, as evidenced by attention, rating, and recall measures (Doherty, 1998). Sonnby-Borgström (2002) investigated differences between participants high and low in emotional empathy and found automatic mimicry to be an early component of this type of empathy. Using electromyographic activity to measure participants' degree of mimicking behavior, high-empathy participants were found to exhibit facial muscle activity and subjective experiences congruent with the mood of presented pictures, whereas low-empathy participants tended to exhibit facial expressions opposite to the stimuli presented. These differences emerged at short exposure times and were interpreted by the author as reflecting automatic reactions. These findings accord with the prediction of Hatfield, Cacioppo, and Rapson (1992) that there is a fast, automatic component of EC, largely inaccessible to awareness, labeled primitive contagion (see also, Hsee, Hatfeld, \& Chemtob, 1992). Hatfield and colleagues also noted that there is a linear relationship between the strength of the facial expressions of the stimulus model and the strength of the evoked emotions in the viewer. Wild, Erb, and Bartels (2001) tested this hypothesis and found that the display of stronger expressions in stimulus models elicited more intense emotions in participants. The researchers presented facial photographs varying in affective content and strength of expressed emotion. After each stimulus, participants rated the strength of experienced feelings; the ratings were positively related to the strength of the perceived emotions in the stimuli.

Hatfield and collaborators (1992) also proposed that women are more susceptible to EC than men because, on average, they react with stronger facial expressions and facial efference theory predicts that 
stronger expressions will tend to elicit stronger emotions (e.g., Zajonc, Murphy, \& Inglehart, 1989). There has been substantial empirical sup- port for this proposal, for instance in two studies with U. S. samples (Doherty, Orimoto, Singelis, Hatfield, \& Hebb, 1995) and in one with a Swedish sample (Lundqvist, 2006); however, the results of the study by Wild and coworkers (2001) did not unambiguously support it, as women reported slightly greater differences in pleasure between happy and sad pictures than men but not more happiness or sadness. It also seems that a sex effect is mediated by other factors. Singelis (1996) used facial reactions to video portrayal of emotions and reported that, although women responded more strongly than men, a feminine role and interdependence self-construal explained most of the variance.

EC has been related to greater reactivity, emotionality, sensitivity to others, social functioning, self-esteem, and empathy (especially emotional rather than cognitive), as well as less alienation, selfassertiveness, and emotional stability (Doherty, 1997). With respect to EC and suggestibility in general, although it is implausible to try to explain complex historical actions such as the Holocaust on its basis (cf. Hatfield et al., 1994), more circumscribed events such as the St. Vitus's and other dance frenzies (Rosen, 1969), and "mass psychogenic illnesses" (e.g., Van Ommeren et al., 2001) are far more likely to have EC and suggestibility as underlying processes. The emotionally charged occurrences around the Mesmeric baquets in 18th-century France were also very likely a strong concoction of EC and other forms of suggestibility (cf. Gauld, 1992).

The hypnotic situation, with its proposed enhancement of rapport (e.g., Brown \& Fromm, 1986) and purposeful shaping of experience through the hypnotist's carefully modulated voice and other techniques, might be a good "laboratory" for the study of EC, especially considering that nonconscious imitation of postures, gestures, and mannerisms increases liking, rapport, and affiliation (Lakin, Jefferis, Cheng, \& Chartrand, 2003). Although we are not aware of a systematic study of this issue in hypnosis, other affect topics have been studied (e.g., Bryant \& McConkey, 1989; Sebastiani, D’Alessandro, Menicucci, Gehlarducci, \& Santarcangelo, 2007). Suggestively, Zimbardo, Marshall, and Maslach (1971) reported some years ago that hypnotic suggestions for a sense of an expanded present enhanced susceptibility to social- emotional contagion. Empathy, which as previously noted correlates positively 
with EC, was found to correlate positively with hypnotizability, as measured by the Harvard Group Scale of Hypnotic Susceptibility, Form A (HGSHS:A; Shor \& Orne, 1962), although the authors cautioned that this correlation might have been affected by having administered both questionnaires in the same context (Wickramasekera \& Szlyk, 2003). Participants' expectancies and consistency motivation are often invoked to explain the stronger correlations between absorption and hypnotizability sometimes found when both are measured in the same context. This effect is often interpreted as an artificial "inflation" (Green \& Council, 2004), but it is by no means obvious what it really indicates. For instance, embedding an absorption measure within an imagination-testing context will produce a context effect, whereas testing absorption as a routine class task does not (Barnier \& McConkey, 1999). Also, Oakman, Woody, and Bowers (1996) reported that often no context effect is found and that when it is present no single explanation seems to account for all the data (see also Jamieson, 2005). One major gap in studies examining context effects has been the reliance on behavioral measures of hypnotizability, excluding phenomenological responses to the hypnotic procedure.

In this paper, we report on two studies examining the relationship between emotional contagion and behavioral and subjective measures of hypnotizability while also evaluating the impact of potential context effects. In Study 1, participants completed a self-report measure of EC during the hypnotic context, whereas in Study 2 other participants completed the EC measure following the hypnotizability assessment, in a nonhypnotic context.

\section{METHOD}

\section{Participants}

Study 1 consisted of 165 participants recruited through announcements at Lund University and in the surrounding communities, ranging in age from 18 to 62 years $(M=28.74, S D=10.39$, two data points missing) and were predominantly female $(n=110$ [67\%]). In Study 2, there were 73 volunteers; this sample was composed entirely of first- year undergraduate psychology students, mostly women $(n=47$ [64\%]), and ranged in age from 19 to 45 years $(M=22.15, S D=3.50)$. The two groups differed in age, 
unequal variance $t(221.83)=7.27, p<.001$, but not in sex distribution, $\chi^{2}(1)=0.23, p>.1$.

\section{Instruments}

The HGSHS: A (Shor \& Orne, 1962) is a widely used, valid, and reliable group measure of hypnotizability with a scoring range of 0 to 12 . Scores for the posthypnotic-amnesia item were derived using the Kihlstrom and Register (1984) criterion of having three or less items recalled before cancellation of the amnesia suggestion and two or more items recalled following the cancellation.

The Subjective Experiences Scale (SES) for the HGSHS:A (Kirsch, Council, \& Wickless, 1990) is a valid and reliable 12-item questionnaire that evaluates how voluntarily or involuntarily the reactions to the items of the HGSHS:A are experienced. Each item is scored using a 5-point Likert response format, and scores range from 12 to 60 .

The Waterloo Stanford Group Scale of Hypnotic Susceptibility, Form C (WSGC; Bowers, 1993, 1998) is a measure of hypnotic ability with good psychometric properties and a scoring range of 0 to 12 . This scale is a group adaptation of the Stanford Hypnotic Susceptibility Scale, Form C (Weitzenhoffer \& Hilgard, 1962).

The Inventory Scale of Hypnotic Depth (ISHD; Field, 1965) is a valid and reliable instrument that includes 38 items measuring different types of subjective experiences empirically associated with hypnosis: (a) absorption and internal and external unawareness, (b) feelings of automaticity and compulsion, and (c) discontinuity from normal experience. The ISHD was used in Study 2 and exhibited strong internal consistency (Cronbach's $\alpha=.88$ ).

The Emotional Contagion Scale (ECS; Doherty, 1997), a 15-item questionnaire that assesses the extent to which individuals automatically experience the emotions of others, with good psychometric properties (e.g., test-retest correlation of .84; Doherty, 1997). It contains positive (love and happiness) and negative (fear, anger, and sadness) emotions subscales, although more complex factorial solutions have been proposed (Lundqvist, 2006). The ECS was administered to participants in both studies and was 
found to exhibit adequate internal consistency in both (Cronbach's $\alpha$; Study $1, \mathrm{ECS}=.80$, ECS positive $=$ $.65, \mathrm{ECS}$ negative $=.80 ;$ Study $2, \mathrm{ECS}=.78, \mathrm{ECS}$ positive $=.68, \mathrm{ECS}$ negative $=.75)$.

\section{Procedure}

All participants provided informed consent. In Study 1, subgroups of participants were sequentially administered the HGSHS:A, the SES, and the ECS in the same context. In Study 2, volunteers were administered the WSGC and the ISHD by the same hypnotist as in Study 1. Approximately 3 months later, a different instructor administered the ECS as part of a class demonstration without any reference to hypnosis or the previous assessment of hypnotizability. This study was approved by the Swedish Federal Human Subjects Agency (Etikprövningsnämden).

\section{Statistical Analyses}

Univariate between-groups analyses of variance were conducted with interval data. Pearson productmoment correlation coefficients were computed to assess correlations, and Fischer's $r$ to $z$ transformations were used to contrast correlations between studies. The significance level was set at .05, two-tailed for all tests.

\section{RESULTS}

Scores on the principal research measures are presented in Table 1. The mean for the HGSHS:A was within the range of other reported data, although slightly lower than the mean when using a Swedish translation (Cardeña, Kallio, Terhune, Buratti, \& Lööf, 2007). The mean for the WSGC was somewhat lower than the means of two North American samples $(M \mathrm{~s}=5.81$ and 5.75; Bowers, 1998). The mean of the scores on the ISHD was very similar to that obtained in the original sample by the author of the measure $(M=14.54$; Field, 1965), whereas the ECS total scores were lower than the norms reported by the author of the measure $(M=3.62$; Doherty, 1997$)$ and by a translator of the measure into Swedish $(M=$ 3.58; Sonnby-Borgström, 2002). These score deflations may stem from the use of the original English 
versions of these scales with Swedish samples. However, our administration of the ECS did not appear to affect the reliability of the scale. ECS scores were significantly higher when EC was measured in the same context as hypnotizability than when measured independently. This was the case for the total ECS scale, the ECS negative scale, and suggestively so for the ECS positive scale.

Table 1

Descriptive Statistics for Dependent Measures

\begin{tabular}{|c|c|c|c|c|c|c|}
\hline & \multicolumn{2}{|c|}{ Study } & \multirow[t]{3}{*}{$F$} & \multirow[t]{3}{*}{$d f$} & \multirow[t]{3}{*}{$p$} & \multirow[t]{3}{*}{$\eta_{p}^{2}$} \\
\hline & $1(n=165)$ & $2(n=73)$ & & & & \\
\hline & $M(S D)$ & $M(S D)$ & & & & \\
\hline HGSHS:A & $5.77(2.68)$ & & & & & \\
\hline SES & $33.82(9.78)^{\mathrm{a}}$ & & & & & \\
\hline WSGC & & $5.10(2.26)$ & & & & \\
\hline ISHD & & $14.44(7.26)$ & & & & \\
\hline ECS & $2.54(0.51)$ & $2.18(0.45)$ & 28.12 & 1,236 & $<.001$ & .11 \\
\hline ECS Positive & $2.98(0.47)$ & $2.85(0.49)$ & 3.41 & 1,236 & .066 & .01 \\
\hline ECS Negative & 3.38 (1.03) & $2.58(0.85)$ & 33.06 & 1,236 & $<.001$ & .12 \\
\hline
\end{tabular}

Note. HGSHS:A = Harvard Group Scale of Hypnotic Susceptibility: Form A; SES = Subjective Experiences Scale; WSGC = Waterloo Stanford Group Scale of Hypnotic Susceptibility; ${ }^{a} n=161$. ISHD = Inventory Scale of Hypnotic Depth; ECS = Emotional Contagion Scale.

Table 2

Research Measures as a Function of Sex and Study

\begin{tabular}{|c|c|c|c|c|c|c|c|}
\hline \multirow[t]{3}{*}{ Variable } & \multirow[t]{3}{*}{ Study } & \multicolumn{2}{|c|}{ Sex } & \multirow[t]{3}{*}{$F$} & \multirow[t]{3}{*}{$d f$} & \multirow[t]{3}{*}{$p$} & \multirow[t]{3}{*}{$\eta_{p}^{2}$} \\
\hline & & Female & Male & & & & \\
\hline & & $M(S D)$ & $M(S D)$ & & & & \\
\hline \multirow[t]{2}{*}{ ECS } & 1 & $2.71(0.45)$ & $2.32(0.42)$ & 47.82 & 1,163 & $<.001$ & .23 \\
\hline & 2 & $2.32(0.42)$ & $1.93(0.39)$ & 14.85 & 1,71 & $<.001$ & .17 \\
\hline \multirow[t]{2}{*}{ ECS Positive } & 1 & $3.04(0.45)$ & $2.85(0.49)$ & 5.83 & 1,163 & .017 & .04 \\
\hline & 2 & $2.92(0.49)$ & $2.75(0.48)$ & 2.06 & 1,71 & .16 & .03 \\
\hline \multirow[t]{2}{*}{ ECS Negative } & 1 & $3.74(0.94)$ & $2.65(0.78)$ & 55.21 & 1,163 & $<.001$ & .25 \\
\hline & 2 & $2.88(0.80)$ & $2.09(0.71)$ & 18.09 & 1,71 & $<.001$ & .20 \\
\hline $\begin{array}{l}\text { HGSHS: } \\
\text { A Objective }\end{array}$ & 1 & $5.94(2.68)$ & 5.42 (2.77) & 1.34 & 1,163 & .25 & .01 \\
\hline SES & 1 & $34.79(9.53)$ & 31.91 (10.07) & 3.15 & 1,159 & .08 & .02 \\
\hline WSGC & 2 & $5.39(2.18)$ & $4.59(2.34)$ & 2.17 & 1,71 & .15 & .03 \\
\hline ISHD & 2 & $15.50(6.39)$ & $12.63(8.36)$ & 2.72 & 1,71 & .10 & .04 \\
\hline
\end{tabular}

In neither Study 1 nor Study 2 did age correlate with the ECS or its subscales (all $p \mathrm{~s}>.1$ ). In Study 1, women scored higher on the ECS and both of it subscales than men; the sex effect was replicated with the ECS and the ECS negative scale in Study 2 (see Table 2). Although not achieving statistical 
significance, women scored higher than men on the HGSHS:A and SES in Study 1 and on the WSGC and ISHD in Study 2.

When administered within the same context (Study 1), both objective and subjective measures of hypnotizability correlated significantly with the ECS and its subscales (see Table 3). In contrast, when measured out of the hypnotic context (Study 2), the ECS did not correlate with the WSGC, but the ISHD did correlate significantly with the ECS positive scale and suggestively so with the ECS total score $(p=$ .063). In order to assess these replication effects, the correlations among the measures in the two studies were contrasted. The correlation between the HGSHS:A and the ECS was greater than the correlation between the WSGC and the ECS, $z=2.36, p<.01$. Similarly, the correlation between the HGSHS:A and the ECS negative scale was greater than that between the WSGC and this scale, $z=2.21, p<.05$, but the correlations between the HGSHS:A and ECS positive scale and the WSGC and ECS positive scale in Samples 1 and 2 did not differ, $z=1.21, p>.05$. Finally, the correlations between the SES and the ECS and its sub- scales and the ISHD and the ECS and its subscales did not differ across the two samples, ECS, $z=0.67, p>.05$; ECS positive, $z=0.33, p>.05$; ECS negative, $z=1.00, p>.05$. These results demonstrate that although Study 2 did not replicate the relationship between a behavioral mea- sure of hypnotizability and EC found in Study 1, the relationship between a subjective measure of hypnotizability and EC was replicated when the latter was measured independently in a nonhypnotic context.

Table 3

Correlation Matrix for the Research Measures in Study $1(n=165)$ and Study $2(n=73)$

\begin{tabular}{llllll}
\hline & WSGC & ECS & $\begin{array}{c}\text { ECS } \\
\text { Positive }\end{array}$ & $\begin{array}{c}\text { ECS } \\
\text { Negative }\end{array}$ & SES \\
\hline HGSHS:A & & $.33^{* * *}$ & $.19^{*}$ & $.31^{* * *}$ & $.83^{* * *}$ \\
ECS & .01 & & $.65^{* * *}$ & $.94^{* * *}$ & $.33^{* * *}$ \\
ECS Positive & .02 & $.66^{* * *}$ & & $.35^{* * *}$ & $.20^{* *}$ \\
ECS Negative & .01 & $.94^{* * *}$ & $.36^{* * *}$ & & $.32^{* * *}$ \\
ISHD & $.45^{* * *}$ & .22 & $.25^{*}$ & .15 & \\
\hline
\end{tabular}

Note. Sample 1 and sample 2 correlation coefficients are presented on the right and left of the diagonal. All sample 1 correlations involving the SES are $n=161$. ${ }^{*} p<.05 ;{ }^{* *} \mathrm{p}<.01 ;{ }^{* * *} \mathrm{p}<.001$. 


\section{DISCUSSION}

As has been reported previously (e.g., Hatfield et al., 1992), women had higher ECS scale and subscale scores than men (in 5 out of 6 comparisons), supporting the cross-cultural validity of this difference, at least for individualistic, Western societies (cf. Cardeña et al., 2007; Singelis, 1996). The higher scores for the ECS when tested along with hypnotizability suggest that participants' responses to the ECS are sensitive to the testing context and may be influenced by it. As predicted, the ECS was significantly related to both behavioral and subjective measures of hypnotizability in Study 1 (in context). The lower means for most of the dependent measures than those published in other studies, while still showing a consistent pattern of reliability, suggest that our range was somewhat depressed by using measures in English, thus probably making our results a conservative estimate of the magnitude of the "true" correlations. The relationship between EC and hypnotizability was not replicated for the behavioral measure (WSGC) when EC was measured in a nonhypnotic context but was replicated for the subjective measure (ISHD). It could be argued that the context effect was spurious because we used different behavioral hypnotizability measures, but the correlation between the HGSHS:A and the WSGC ( $r=.70$; Bowers, 1998) and the .01 correlation between the EC and the WSGC renders this unlikely. A likelier, but so far untested, hypothesis is that because the WSGC uses more cognitive suggestions than the HGSHS:A, the relationship between EC and hypnotizability may be stronger with behavioral than with cognitive items, which load on different factors (Woody, Barnier, \& McConkey, 2005), particularly considering that most of the items of the ECS refer to emotions and behaviors rather than cognitions.

The finding that subjective measures of hypnosis may effect more significant correlations than behavioral indexes is similar to that of a previous study (Cardeña, 1993), also using an out-of-context protocol, wherein a subjective measure of hypnotizability (SES) exhibited a stronger relationship with a measure of feelings and other mental boundaries subscales (cf. Hartmann, 1989) than a behavioral measure (HGSHS:A). These results are consistent with Weitzenhoffer's (1980) position that what really characterizes hypnosis is alterations in the subjective experience of the respondent (e.g., involuntariness for suggested responses), rather than behavioral responses, which could be just a matter of compliance. 
Thus, previous results assessing the relationship of exclusively behavioral measures of hypnotizability may provide an incomplete picture of the hypnosis domain.

Conceptually, EC would seem to be closer to what Gheorghiu (1989) called "secondary suggestibility," that is, responsivity to indirect suggestions rather than to primary suggestibility involving overt suggestions (Cardeña \& Spiegel, 1991), but this categorization does not quite seem to do justice to EC, which besides automatic responses may involve awareness of the emotion being perceived. In any event, we have presented evidence that highly hypnotizable individuals may be more likely to mimic the emotional tone and behaviors of others than nonhypnotizable ones. This is a point often made in hypnosis training but so far as we know it has not been directly tested.

We also found a context effect for some but not all measures, which makes an interpretation of this effect particularly thorny. First, ECS scores were significantly higher when administration followed a hypnotizability test than when the measures were administered independently of one another. Although the two samples differed in age, the context effect cannot be explained by recourse to age as it did not correlate with EC. Beside the possibility that testing in context may enhance expectancies for similar performance in related tests, Roche and McConkey (1990) proposed that the hypnotic context has a priming effect that triggers relevant representations and encourages respondents to think more about experiences (including EC ones) that might be more salient, thus making correlations within the same context testing more rather than less valid.

We found that two different measures of subjective hypnotic responding, in and out of context, correlated significantly with the ECS, and the magnitude of the correlation coefficient was very similar to that found in a study comparing hypnotizability and empathy (Wickramasekera \& Szlyk, 2003), which may be taken as support for the position that EC and empathy are similar constructs. The relation- ship between the behavioral measures of hypnosis and the ECS was not found when administered independently of one another, which may indicate the need for a "priming" effect for this relationship to manifest.

Woody and Szechtman (2007) recently proposed that an affective component, the "feeling of 
knowing," underlies hypnotic responses and further speculate that hypnosis may be based on a tendency to become submissive towards the hypnotist. This proposal follows a long tradition in hypnosis of considering the hypnotist an authority or parental figure such as in Shor's (1962) notion of "archaic involvement" (transference). Nash and Spinler (1989) found that three clusters of their measure of archaic involvement were correlated with hypnotizability: perceived power of the hypnotist, positive emotional involvement, and fear of negative appraisal. Steven Jay Lynn and his group (e.g., Lynn et al., 1991) also found that the type of rapport produced by the hypnotist affected emotions toward the hypnotist and hypnotizability levels, especially among low hypnotizables.

Our results, although supporting a connection between hypnosis and a covert, affective component (notice the partly automatic nature of EC), suggest that hypnosis may involve a more general tendency to be affected by the emotions of others. Also relevant is the recent finding that a mirror neuronal system, which is responsible for the activation of the same brain areas during experience as during passive observation of somebody else's similar behavior, has been implicated in empathy, specifically so with mirror-touch (or vision-touch) synesthetes. These individuals experience tactile sensations when observing others being touched and exhibit greater emotional reactivity (but not cognitive empathy or social skills) than controls and other synesthetes (Banissy \& Ward, 2007). The experience of stimulus-congruent multi-modal imagery and/or perceptions (e.g., experiencing cold while admiring a painting of a snowstorm) can be conceptualized as a form of weak synesthesia (Marks, 2000) and has been found to correlate with hypnotizability (Jamieson, 2005). Synesthesia also arguably represents a component of absorption (Ott, 2007; Tellegen \& Atkinson, 1974), and the latter is positively correlated with emotional empathy (Wickramasekera, 2007). More research and conceptual attention should be directed to the interrelationships among absorption, emotional contagion, emotional empathy, synesthesia, and the mirror-neuron system (cf. Dieguez, 2005).

There are some limitations to this study; foremost, we believe, is the evaluation of EC with a selfreport measure. Although the scale has strong psychometric properties, other behavioral and cognitive mea- sures are likely to provide more substantive information regarding the relationship between 
hypnotizability and emotional contagion. We also administered measures in their original language (English), but, as mentioned earlier, there is reason to believe that although this may have depressed the scores slightly the measures remained valid and reliable. It should also be stated that the relationship between hypnotizability and EC is of such magnitude as to suggest that these constructs may have one or more similar mechanisms but also diverge in important ways; thus, EC cannot be reduced to hypnotizability or vice-versa.

Although the authority of the hypnotist probably has some bearing on hypnotizability, other aspects are also germane. They include the ability to feel or appear to feel strong emotions, to be able to express them, and to be insensitive to incompatible emotions (Hatfield et al., 1994, p. 146), features that also characterize acting (Cardeña \& Beard, 1996). Researchers should pay more attention to how the characteristics and behaviors of the hypnotist affect the hypnosis experience, including related affective responses (Barber, 1999).

\section{REFERENCES}

Banissy, M. J., \& Ward, J. (2007). Mirror-touch synesthesia is linked with empathy. Nature Neuroscience, 10, 815-816.

Barber, T. X. (1999). A comprehensive three-dimensional theory of hypnosis. In I. Kirsch, A. Capafons, E. Cardeña, \& S. Amigó (Eds.), Clinical hypnosis and self-regulation (pp. 21-48). Washington, DC: American Psychological Association.

Barnier, A. J., \& McConkey, K. M. (1999). Absorption, hypnotizability and context: Non- hypnotic contexts are not all the same. Contemporary Hypnosis, 16, 1-8.

Barsade, S. G. (2002). The ripple effects: Emotional contagion and its influence on group behavior. Administrative Sciences Quarterly, 47, 644-675.

Bowers, K. S. (1993). The Waterloo-Stanford Group C (WSGC) Scale of Hypnotic Susceptibility: Normative and comparative data. International Journal of Clinical and Experimental Hypnosis, 41, $35-46$. 
Bowers, K. S. (1998). Waterloo-Stanford Group Scale of Hypnotic Susceptibility, Form C: Manual and response booklet. International Journal of Clinical and Experimental Hypnosis, 46, 250-268.

Brown, D. P., \& Fromm, E. (1986). Hypnotherapy and hypnoanalysis. Hillsdale, NJ: Erlbaum.

Bryant, R. A., \& McConkey, K. M. (1989). Hypnotic emotions and physical sensations: A realstimulating analysis. International Journal of Clinical and Experimental Hypnosis, 37, 305-319.

Cardeña, E. (1993). Hypnotizability and mental boundaries. A correlational study. International Journal of Clinical and Experimental Hypnosis, 41, 331.

Cardeña, E., \& Beard, J. (1996). Truthful trickery: Shamanism, acting and reality. Performance Research, $1,31-39$.

Cardeña, E., Kallio, S., Terhune, D., Buratti, S., \& Lööf, A. (2007). The effect of translation and sex on hypnotizability testing. Contemporary Hypnosis, 24, 154-160.

Cardeña, E., \& Spiegel, D. (1991). Suggestibility, absorption, and dissociation: An integrative model of hypnosis. In J. F. Schumaker (Ed.), Human suggestibility: Advances in theory, research and application (pp. 93-107). New York: Routledge.

Dieguez, S. (2005). Vers una neuropsychologie sociale [Towards a social neuropsychology]. Schweizer archiv für neurology und psychiatrie, 156, 147-172.

Doherty, R. W. (1997). The Emotional Contagion Scale: A measure of individual differ- ences. Journal of Nonverbal Behavior, 21, 131-154.

Doherty, R. W. (1998). Emotional contagion and social judgment. Motivation and Emotion, 22, 187-209.

Doherty, R. W., Orimoto, L., Singelis, T. M., Hatfield, E., \& Hebb, J. (1995). Emotional contagion: Gender and occupational differences. Psychology of Women Quarterly, 19, 355-371.

Field, P. B. (1965). An inventory scale of hypnotic depth. International Journal of Clinical and Experimental Hypnosis, 13, 238-249.

Gauld, A. (1992). A history of hypnotism. Cambridge, UK: Cambridge University Press. Gheorghiu, V. A. (1989). The development of research o suggestibility: Critical considerations. In V. A. Gheorghiu, P. Netter, H. J. Eysenck, \& R. Rosenthal (Eds.), Suggestion and suggestibility: Theory and research (pp. 
3-56). New York: Springer-Verlag.

Green, J. P., \& Council, J. R. (2004). Does the positive keying of the TAS inflate the absorptionhypnotizability link? International Journal of Clinical and Experimental Hypnosis, 52, 378-388.

Hartmann, E. (1989). The nightmare. New York, NY: Basic Books.

Hatfield, E., Cacioppo, J. T., \& Rapson, R. L. (1992). Primitive emotional contagion. Review of Personal and Social Psychology, 14, 151-177.

Hatfield, E., Cacioppo, J., \& Rapson, R. (1994). Emotional contagion. New York: Cambridge University Press.

Hsee, C. K., Hatfield, E., \& Chemtob, C. (1992). Assessments of the emotional states of others:vConscious judgments versus emotional contagion. Journal of Social \& Clinical Psychology, $11,119-128$.

Jamieson, G. A. (2005). The modified Tellegen Absorption Scale: A clearer window on the structure and meaning of absorption. Australian Journal of Clinical and Experimental Hypnosis, 33, 119-139.

Kihlstrom, J. F., \& Register, P. A. (1984). Optimal scoring of amnesia on the Harvard Group Scale of Hypnotic Susceptibility, Form A. International Journal of Clinical and Experimental Hypnosis, 32, $51-57$.

Kirsch, I., Council, J. R., \& Wickless, C. (1990). Subjective scoring for the Harvard Group Scale of Hypnotic Susceptibility, Form A. International Journal of Clinical and Experimental Hypnosis, 38, $112-124$.

Lakin, J. L., Jefferis, V. E., Cheng, M., \&, Chartrand, T. L. (2003). The chameleon effect as social glue: Evidence for the evolutionary significance of nonconscious mimicry. Journal of Nonverbal Behavior, 27, 145-162.

Levenson, R. W., \& Ruef, A. M. (1997). Physiological aspects of emotional knowledge and rapport. In W. J. Ickes (Ed.), Empathic accuracy (pp. 44-72). New York, NY: Guilford.

Lundqvist, L. O. (2006). A Swedish adaptation of the Emotional Contagion Scale: Factor structure and psychometric properties. Scandinavian Journal of Psychology, 47, 263-272. 
Lynn, S. J., Weekes, J. R., Neufeld, V., Zivney, O., Brentar, J., \& Weiss, F. (1991). Interpersonal climate and hypnotizability level: Effects on hypnotic performance, rapport, and archaic involvement. Journal of Personality and Social Psychology, 60, 739-743.

Marks, L. E. (2000). Synesthesia. In E. Cardeña, S. J. Lynn., \& S. Krippner (Eds.), Varieties of anomalous experience (pp. 121-149). Washington, DC: American Psychological Association.

Nash, M. R., \& Spinler, D. (1989). Hypnosis and transference: A measure of archaic involvement with the hypnotist. International Journal of Clinical and Experimental Hypnosis, 37, 129-144.

Oakman, J. M., Woody, E. Z., \& Bowers, K. S. (1996). Contextual influences on the relationship between absorption and hypnotic ability. Contemporary Hypnosis, 13, 19-28.

Ott, U. (2007). States of absorption: In search of neurobiological foundations. In G. A. Jamieson (Ed.), Hypnosis and conscious states: The cognitive neuroscience perspective (pp. 257-270). Oxford, UK: Oxford University Press.

Roche, S., \& McConkey, K. M. (1990). Absorption: Nature, assessment, and correlates. Journal of Personality and Social Psychology, 59, 91-101.

Rosen, G. (1969). Madness in society. Chapters in the historical sociology of mental illness. New York, NY: Harper.

Sebastiani, L., D’Alessandro, L., Menicucci, D., Gehlarducci, B., \& Santarcangelo, E. L. (2007). Role of relaxation and specific suggestions in hypnotic emotional numbing. International Journal of Psychophysiology, 63, 125-132.

Shor, R. E. (1962). Three dimensions of hypnotic depth. International Journal of Clinical and Experimental Hypnosis, 10, 23-38.

Shor, R. E., \& Orne, E. C. (1962). Harvard Group Scale of Hypnotic Susceptibility, Form A. Palo Alto, CA: Consulting Psychologists Press.

Singelis, T. M. (1996). The effects of culture, gender, and self-construal on emotional contagion. Dissertation Abstracts International: Section B: The Sciences and Engineering, 56(10-B), 5839.

Sonnby-Borgström, M. (2002). Automatic mimicry reactions as related to differences in emotional 
empathy. Scandinavian Journal of Psychology, 43, 433-443.

Tellegen, A., \& Atkinson, G. (1974). Openness to absorbing and self-altering experiences ("absorption"), a trait related to hypnotic susceptibility. Journal of Abnormal Psychology, 83, 268-277.

Van Ommeren, M. V., Sharma, B., Komproe, I., Sharma, G. K., Cardeña, E., de Jong, et al. (2001). Trauma and loss as determinants of medically unexplained epidemic illness in a Bhutanese refugee camp. Psychological Medicine, 31, 1259-1267.

Weitzenhoffer, A. (1980). Hypnotic susceptibility revisited. American Journal of Clinical Hypnosis, 22, $130-146$.

Weitzenhoffer, A. M., \& Hilgard, E. R. (1962). Stanford Hypnotic Susceptibility. Scale, Form C. Palo Alto, CA: Consulting Psychologists Press.

Wickramasekera, I., II. (2007). Empathic features of absorption and incongruence. American Journal of Clinical Hypnosis, 50, 59-69.

Wickramasekera, I. E., II, \& Szlyk, J. P. (2003). Could empathy be a predictor of hypnotic ability? International Journal of Clinical \& Experimental Hypnosis, 51, 390-399.

Wild, B., Erb, M., \& Bartels, M. (2001). Are emotions contagious? Evoked emotions while viewing emotionally expressive faces: Quality, quantity, time course and gender differences. Psychiatry Research, 102, 109-124.

Woody, E. Z., Barnier, A. J., \& McConkey, K. M. (2005). Multiple hypnotizabilities: Differentiating the building blocks of hypnotic response. Psychological Assessment, 17, 200-211.

Woody, E., \& Szechtman, H. (2007). To see feelingly: Emotion, motivation and hypnosis. In G. A. Jamieson (Ed.), Hypnosis and conscious states: The cognitive neuroscience perspective (pp. 241255). Oxford, UK: Oxford University Press.

Zajonc, R. B., Murphy, S. T., \& Inglehart, M. (1989). Feeling and facial efference: Implications of the vascular theory of emotion. Psychological Review, 96, 395-416.

Zimbardo, P. G., Marshall, G., \& Maslach, C. (1971). Liberating behavior from time-bound control: Expanding the present through hypnosis. Journal of Applied Social Psychology, 1, 305-323. 
